\title{
Analysis of an Auxiliary Power Supply Transfer Failure of High Speed Transfer Device in an Extended Power Plant
}

\author{
Zhang Ping, Yang Tian, Zhu Hao-rang, \\ HuaDian Electric Power Research Institute Co.,LTD , China
}

\begin{abstract}
In modern power enterprises, the stability of auxiliary power supply is related to the safe and stable operation of units, so the high spee

amage in serious cases. This paper could provide reference for safety operation through a case of transfer failure of high-voltage auxiliary power transfer device in an expansion power plant.
\end{abstract}

\section{Preface}

In the operation of modern power system, once the auxiliary power is supplied by disturbance power, it would cause unplanned shutdowns, which will seriously affect the safety of the power plant. Power transfer is a complex electromechanical process, especially in the process of accident transfer which the current, voltage, frequency, phase angle of the transfer device would change rapidly. If transferring improperly, it would cause transfer failure, equipment damage even unit shutdown. Therefore, to ensure the safe and reliable operation of high auxiliary power supply, the generator set is equipped with high speed transfer device to ensure the continued supply to the consumer through automatic transferring to a stand-by power supply and protects the subsidiary process from expensive stoppage time[1].

\section{Principle of the High Speed Transfer Device for Auxiliary Power Transfer}

The safety and reliability of auxiliary power is related to the fixed operation of generator set, power plant and even the whole power system. The timely switching of auxiliary power is an important part of the safety and reliability of auxiliary power. Electronic control system is widely used in the high speed transfer device in the power plants. In the transferring process, the auxiliary contact point is used to start the working form of the stand-by power supply directly. A fast transfer takes place by capturing and analysing the voltage, frequency and phase difference between the main and the stand-by power supply[2,3].

This paper takes the 'WBKQ-01C' HSTD of Guodian Nanzi Company as an example.

With this configuration, the HSTD has manually transfer, accident transfer and abnormal working condition transfer. Manually transfer refers to the transfer between the main and the stand-by power supply under normal conditions, for two incoming power supply and busbar form, 1DL (main breaker) and 2DL (stand-by breaker) could be transferred. Manually transfer could be divided into parallel transfer, series transfer and simultaneous transfer. If the condition of parallel transfer after manually-initiated is not satisfied, the device would delay $10 \mathrm{~S}$ and send a blocking signal, waiting for manual reset. Accident transfer refers to the generatortransformer and auxiliary transformer protection. Accident transfer includes accident series transfer and accident simultaneous transfer. The transfer functions under abnormal conditions include bus low voltage transfer and switch secret trip transfer.

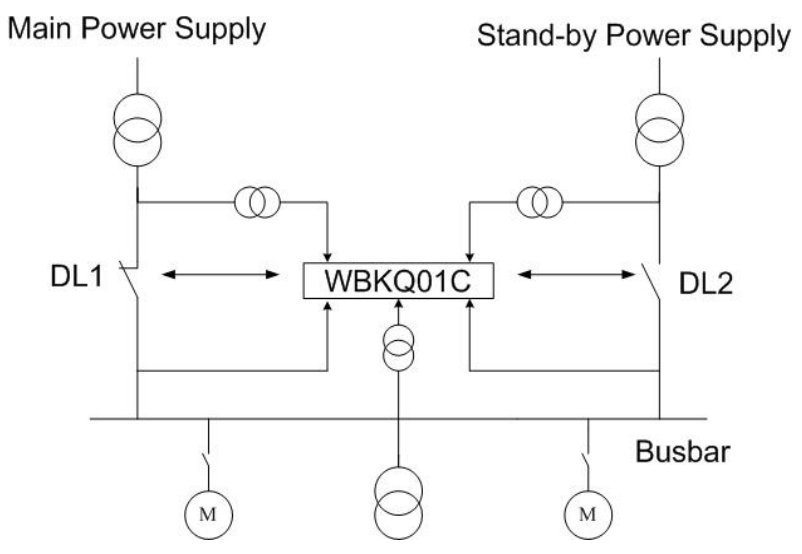

Fig. 1. HSTD Schematic diagram

\section{Analysis of Auxiliary Power Supply Fast Transfer Failure Process}

Taking an $2 \times 1000 \mathrm{MW}$ thermal power plant extension project as an example, two $10 \mathrm{kV}$ busbar were set for each unit shown in Fig. 2 below. 


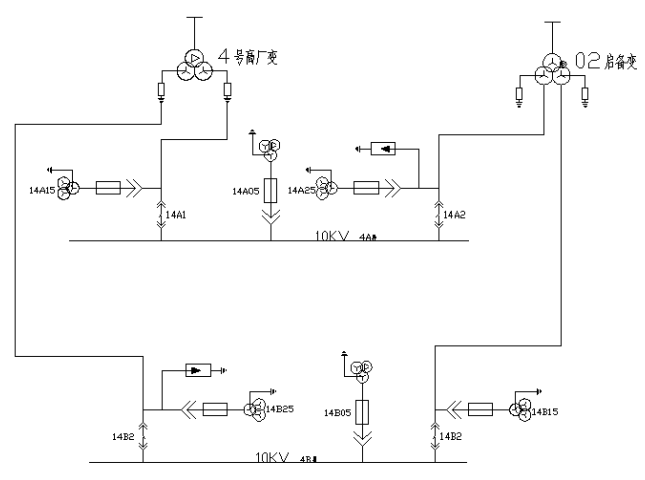

Fig. 2. diagrammatic sketch of Auxiliary power system

Distribution equipment in booster station was connected with an winding split on-load voltage-regulating transformer as stand-by power supply for two auxiliary busbar,and one double-winding-split auxiliary transformer is specially installed as main power supply for auxiliary busbar. Each auxiliary busbar is equipped with a set of WBKQ-01C high speed transfer device, which is used for manually and accident transfer.

During the disconnection and shutdown of Unit 2 , The operator fail to manually parallel transfer the standby power supply of the $10 \mathrm{kV} 2 \mathrm{~B}$ busbar, The signal of 'fast transfer device blocking' was reported. The stand-by power supply circuit breaker was in open position. The DCS system showed that the status of the main power supply and standby power supply circuit breaker was displayed correctly, during the switchover process, the status of stand-by power supply circuit breaker did not changed, no protection on or other abnormalities occurred. Operators check that $110 \mathrm{~V}$ DC power supply of the $10 \mathrm{kV} 2 \mathrm{~B}$ standby power supply circuit breaker cabinet was normal, 'power trip', 'power close', 'standby power trip', and 'standby power close ' hard straps of $10 \mathrm{kV} 2 \mathrm{~B}$ high speed transfer device were put in correctly.

On-spot inspection found that the protection setting, the contact status of the main and the stand-by power supply circuit breaker, the secondary value of main and the stand-by power supply PT voltage and busbar PT voltage of the $10 \mathrm{kV} 2 \mathrm{~B}$ busbar high speed transfer device, were correct shown in Table. 1 and Table. 2 below; the instruction and feedback signal circuit of DCS to the $10 \mathrm{kV}$ 2B busbar HSTD was correct; The secondary circuit of the $10 \mathrm{kV} 2 \mathrm{~B}$ busbar HSTD to the main power supply circuit breaker cabinet and the standby-power power supply were correct. There was no 'blocking' signal after the HSTD was restored, so the HSTD had the transfer conditions. According to the above conditions, it could be judged that the $10 \mathrm{kV} 2 \mathrm{~B}$ busbar HSTD was working correctly. It was suspected that the failure of transferred was caused by the fault of the stand-by power supply circuit breaker cabinet.
Table.1. Secondary voltage amplitude

\begin{tabular}{|c|c|c|c|}
\hline Voltage amplitude & $\mathbf{U}_{\mathbf{a b}}$ & $\mathbf{U}_{\mathbf{b c}}$ & $\mathbf{U}_{\mathbf{c a}}$ \\
\hline 10kV Mainy power supply & 100.5 & 100.5 & 100.5 \\
\hline 10kV busbar & 100.5 & 100.5 & 100.5 \\
\hline $\begin{array}{c}\text { 10kV stand-by power } \\
\text { supply }\end{array}$ & 99.9 & 99.9 & 100.0 \\
\hline
\end{tabular}

Table.2. Secondary voltage phase sequence

\begin{tabular}{|c|c|c|c|}
\hline Phase sequence & $\mathbf{U}_{\mathbf{a b}}$ & $\mathbf{U}_{\mathbf{b c}}$ & $\mathbf{U}_{\mathbf{c a}}$ \\
\hline 10kV Mainy power supply & 0 & 239.9 & 120.1 \\
\hline 10kV busbar & 0 & 239.9 & 120.1 \\
\hline $\begin{array}{c}\text { 10kV stand-by power } \\
\text { supply }\end{array}$ & 0 & 240.4 & 119.7 \\
\hline
\end{tabular}

Measuring the voltage difference between $110 \mathrm{~V}$ DC secondary closing circuit of stand-by power supply circuit breaker in $10 \mathrm{kV} 2 \mathrm{~B}$ busbar HSTD was only $57.6 \mathrm{~V}$, Its secondary 'positive' circuit to the ground was $57.6 \mathrm{~V}$ to the ground and its secondary 'negative' circuit the ground was $0.1 \mathrm{~V}$ to. Normally, when the stand-by power supply circuit breaker is in opening position, the voltage difference between 110 DC secondary closing circuit of stand-by power supply circuit breaker in the $10 \mathrm{kV} 2 \mathrm{~B}$ busbar HSTD should be about $115 \mathrm{~V}$. In which its secondary 'positive' and 'negative' circuit to ground should be about $\pm 57.5 \mathrm{~V}$. It could be concluded that the secondary closing circuit of stand-by power supply circuit breaker was open, and the failure of the secondary closing circuit leads to the unsuccessful manual parallel transfer of the $10 \mathrm{kV} 2 \mathrm{~B}$ busbar.

ABB switch cabinet was used in the $10 \mathrm{kV}$ busbar of the two units in the extension project. The principle of the $10 \mathrm{kV}$ busbar stand-by power supply circuit breaker cabinet trip-monitoring and fast transfer circuit is shown in Fig. 3 below.

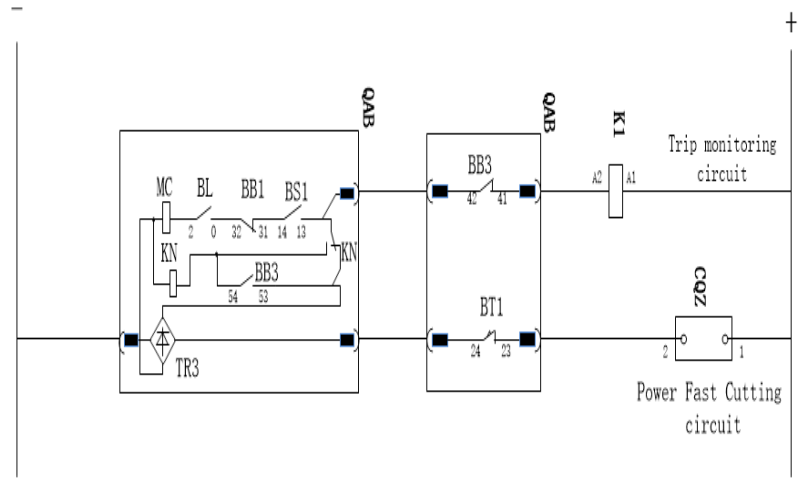

Fig. 3. Trip-monitoring and Fast Transfer circuit Schematic Diagram

In Figure 3, QAB is the internal wiring diagram of the circuit breaker, BS1 is the auxiliary switch of the energy storage mechanism of the circuit breaker, BS1 13 
and 14 are its pair of N.O. contacts; BB1 and BB3 are auxiliary switches of the circuit breaker, BB1 31, 32 and BB3 41 and 42 are their N.C. contacts; BL is the open blocking electromagnet auxiliary switch of the circuit breaker, BL0 and 2 are its pair of N.O. contacts; BT1 is the limit switch of the handcart's operating position, BT1 23, 24 is a pair of N.C. contacts, MC is a circuit breaker closing tripper, $\mathrm{KN}$ is the skip-prevention relay, $\mathrm{K} 1$ is the off-position monitoring relay, and CQZ is the HSTD closing contact.

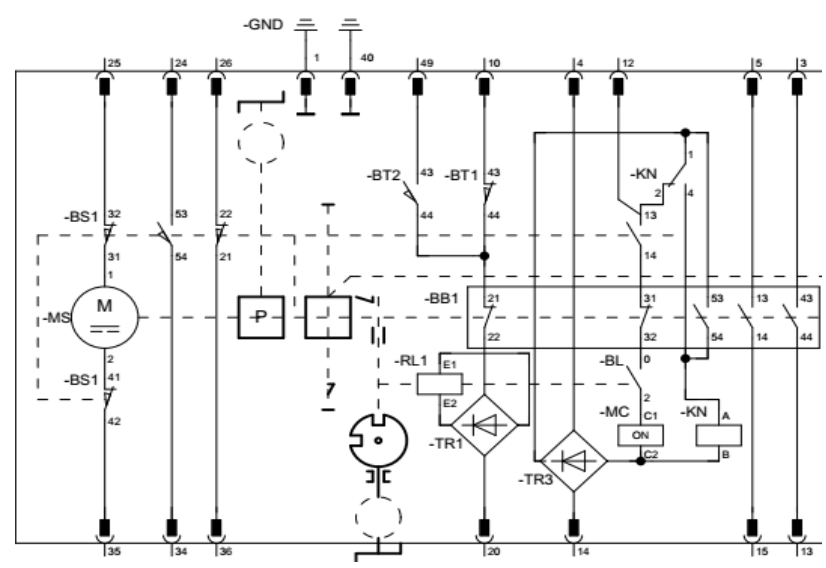

Fig. 4. Circuit Breaker QAB Internal Schematic Diagram

It was found in the on-spot inspection that the indicator K1 was off, and N.C. contacts BB3:41, 42 were measured closed; N.C. contacts BT1:23, 24 were measured; at the same time, the energy storage mechanism was in good condition, and the open blocking electromagnetic auxiliary switch BL was closed. From figs. 3 and 4, it could be judged that the $10 \mathrm{kV} 2 \mathrm{~B}$ stand-by power supply circuit breaker auxiliary switch N.C. contacts BB1:31,32 were faulty. Dragging the $10 \mathrm{kV} 2 \mathrm{~B}$ stand-by power supply circuit breaker handcart out of the cabinet, measuring the N.C. points BB1:31, 32, it could be found that the contacts were open. This could judge that the N.C. contacts BB1:31, 32 were faulty, which result in abnormal operation of TR3, 110V DC positive circuit couldn't supply the switching monitoring circuit and the CQZ closing circuit and failed to manually parallel transfer the stand-by power supply of $10 \mathrm{kV} 2 \mathrm{~B}$ busbar.

\section{Solution}

Finding another pair of N.C. contact 41 and 42, which could be connected in parallel with the auxiliary switches BB1 N.C. contacts 31 and 32 to ensure closed reliably, as shown in Fig. 5 after modification.

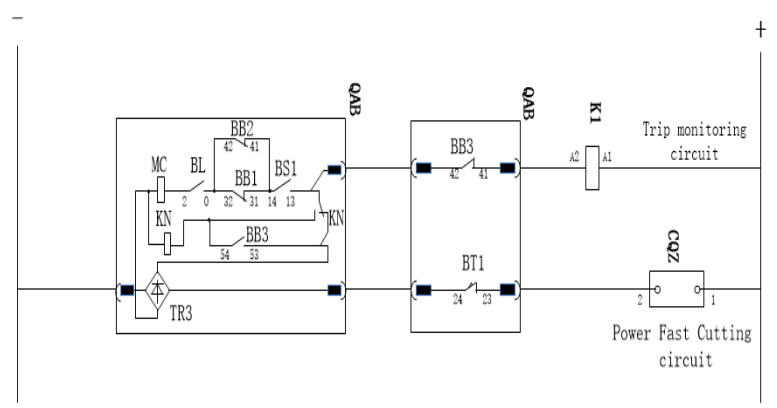

Fig. 5. Trip-monitoring and Fast Transfer circuit After Modification Schematic Diagram

After the modification was completed, the $10 \mathrm{kV} 2 \mathrm{~B}$ stand-by power supply circuit breaker was in working condition and $110 \mathrm{~V}$ DC power supply was sent to the switch cabinet. The voltage difference between $110 \mathrm{~V}$ DC secondary closing circuit of stand-by power supply circuit breaker in the $10 \mathrm{kV} 2 \mathrm{~B}$ busbar HSTD was measured $115.3 \mathrm{~V}$. Its secondary 'positive' circuit to ground is $57.6 \mathrm{~V}$ and its secondary 'negative' circuit to ground is $-57.7 \mathrm{~V}$. The green light of the indicator K1 was on, which means the manual parallel transfer of standby power supply for $10 \mathrm{kV} 2 \mathrm{~B}$ busbar was successful.

\section{Conclusion}

From the above analysis, it could be seen that the failure transfer from main to stand-by power supply of the Unit $210 \mathrm{kV} 2 \mathrm{~B}$ busbar is due to the abnormal of N.C. contacts BB1:31, 32 in the control circuit of stand-by power supply circuit breaker. This lead to the circuit breaker could not close, which result in the block of the HSTD. In order to prevent such malfunction happening again in the Unit operation, firstly it is necessary to strengthen the inspection of the switch and the cabinet. After the switch test, the operator should check the correctness of the on and off-position monitoring relay $\mathrm{K} 1$ and $\mathrm{K} 2$ status indicators to repair and replace the circuit breaker if necessary. Moreover, strengthen the operation and maintenance of HSTD to ensure the correct function. Third, if the technology permitted, the normal transfer of auxiliary power supply should adopt manual parallel transfer mode to prevent the faulty of circuit breaker result in the transfer failure even enlarge the accident. Finally, it is necessary to strengthen the training of power plant operation and maintenance personnel so that they could understand and master the working principle of high speed transfer system, accident inspection and treatment methods, so as to ensure the correct and reliable operation of HSTD.

\section{References}

1. Northwest electric power design institute.Power Engineering Electrical Design Manual Secondary part[M].Beijing:China Electric Power Press.1996 
2. Mei Xinghu, Guo Wei. Application and research of fast switching technology for auxiliary power[J]. Papers Collection of the 24th Annual Academic Conference of Electric Power System and Automation Specialty in Chinese Colleges and Universities, 796-798

3. Sha li.The application of auxiliary power system rapid switching-over techonlogy in power plant[J].Jiangsu

ElectricaEngineering,2004,23(6),44-46.

4. Ahmed Abdelmoaty, Mohammad Al-Shyoukh, Ayman Fayed. A high-voltagelevel shifter with sub-nano-second propagation delay for switching powerconverters. IEEE, 2016(05): 20-24.

5. Ahmed Abdelmoaty, Mohammad Al-Shyoukh, Ayman Fayed. A high-voltagelevel shifter with sub-nano-second propagation delay for switching powerconverters. IEEE, 2016(05): 20-24. 